Georgia State University

ScholarWorks @ Georgia State University

\title{
Transgender Individuals' Access to College Housing and Bathrooms: Findings from the National Transgender Discrimination Survey
}

Kristie L. Seelman

Georgia State University, kseelman@gsu.edu

Follow this and additional works at: https://scholarworks.gsu.edu/ssw_facpub

Part of the Gender and Sexuality Commons, Higher Education Commons, and the Social Work Commons

\section{Recommended Citation}

Seelman, Kristie L., "Transgender Individuals' Access to College Housing and Bathrooms: Findings from the National Transgender Discrimination Survey" (2014). SW Publications. 57.

https://scholarworks.gsu.edu/ssw_facpub/57

This Article is brought to you for free and open access by the School of Social Work at ScholarWorks @ Georgia State University. It has been accepted for inclusion in SW Publications by an authorized administrator of ScholarWorks@ @eorgia State University. For more information, please contact scholarworks@gsu.edu. 
Running head: TRANSGENDER ACCESS TO HOUSING AND BATHROOMS

Transgender Individuals' Access to College Housing and Bathrooms:

Findings from the National Transgender Discrimination Survey

Kristie L. Seelman

University of Denver

This is an Author's Accepted Manuscript of an article published in the Journal of Gay and Lesbian Social Services, May 15, 2014, available online: http://www.tandfonline.com/10.1080/10538720.2014.891091

Author Note

Kristie L. Seelman, Graduate School of Social Work, University of Denver.

Kristie L. Seelman is now at the School of Social Work, Andrew Young School of Policy Studies, Georgia State University.

This study was conducted as part of a dissertation, and portions of the literature review, methodology, and results are adapted from this source. The National Gay and Lesbian Task Force and the National Center for Transgender Equality conducted the National Transgender Discrimination Survey, which generated the data analyzed within this research. Their report on the survey data is available from the National Center for Transgender Equality website (http://transequality.org).

Funding support for this research was provided by an American Fellowship from the American Association of University Women, a Dissertation Fellowship from the University of 
Denver Office of Graduate Studies, and a Dissertation Support Award from the University of Denver Graduate School of Social Work. I am grateful to my dissertation committee (Dr. Eugene Walls, Dr. Nicole Nicotera, and Dr. Walter LaMendola) for their encouragement and mentoring related to this project and to Dr. Nancy Kropf and Dr. Sarah Nickels for their invaluable feedback on drafts of this manuscript.

Correspondence concerning this article should be addressed to Kristie L. Seelman, School of Social Work, Andrew Young School of Policy Studies, Georgia State University, PO Box 3995, Atlanta, GA 30302-3995. E-mail: kseelman@gsu.edu 


\begin{abstract}
Within higher education settings, transgender people are at risk for discrimination and harassment within housing and bathrooms. Yet, few have examined this topic using quantitative data or compared the experiences of subgroups of transgender individuals to predict denial of access to these spaces. The current study utilizes the National Transgender Discrimination Survey to research this issue. Findings indicate that being transgender and having another marginalized identity matters for students' access to housing and bathrooms. Trans women are at greater risk than gender non-conforming people for being denied access to school housing and bathrooms. Implications for practice and research are detailed.
\end{abstract}

Key words: transgender, higher education, discrimination, housing, bathrooms 
Transgender Individuals' Access to College Housing and Bathrooms:

Findings from the National Transgender Discrimination Survey

An increasing proportion of young people and adults in the U.S. are choosing to attend a college or university. While in 1960 , only $45.1 \%$ of youth recently completing high school entered a two- or four-year college, by 2010, the proportion had risen to $68.1 \%$ (U.S. Department of Education, n.d.). As the number of college students grows, our society must prepare for creating higher education institutions that respond to the needs of a diverse population of learners. However, many institutions struggle with meeting the needs of students from marginalized populations, including those who identify as transgender or gender non-conforming.

While some universities are taking proactive steps to welcome and include transgender individuals through actions such as expanding their nondiscrimination policies (Campus Pride Trans Policy Clearinghouse, n.d.), Beemyn (2005a) argues that colleges and universities need to give thought to how their very structure - physical and social — upholds a binary conceptualization of gender. Examples of institutional features that exclude or place transgender people at risk for discrimination and harassment are the predominance of sex-segregated bathrooms, locker rooms, and housing where transgender people regularly are denied access, harassed, and challenged about their gender identity (Beemyn, 2005a; Beemyn, Curtis, Davis, \& Tubbs, 2005; Bilodeau, 2007; Finger, 2010; Seelman et al., 2012). When such situations occur, these spaces become unsafe and stress-inducing environments.

While there are a number of qualitative studies that explore access to gendered spaces on campus using small, purposive samples (e.g., Bilodeau, 2007; Finger, 2010; Seelman et al., 2012), few studies analyze this topic using quantitative data to predict factors associated with denial of access to such space. The current study aims to examine these risks through an analysis 
of data from the National Transgender Discrimination Survey, which was designed and conducted by the National Gay and Lesbian Task Force (the Task Force) and the National Center for Transgender Equality (NCTE; Grant et al., 2011).

Before reviewing the literature, I will first provide an explanation of the word transgender as it will be used in this paper. The term transgender encompasses "a range of gender experiences, subjectivities and presentations that fall across, between or beyond stable categories of 'man' and 'woman'... [including] gender identities that have, more traditionally, been described as 'transsexual,' and a diversity of genders that call into question an assumed relationship between gender identity and presentation and the 'sexed' body" (Hines, 2010, p. 1). This includes those who identify as male-to-female (MTF, or trans women), female-to-male (FTM, or trans men), genderqueer, two-spirit, androgynous, and other gender identities. I will often partner the word transgender (or simply trans) with the phrase gender non-conforming to acknowledge those who reject or do not agree with gender binaries but who may not identify as transgender. My use of the word transgender includes those who have undergone medical treatment to physically transition (i.e., received hormone treatment and/or undergone one or more surgeries as part of transitioning from one gender to another), although not everyone who is transgender desires to go through or can afford such medical treatments. While there are important distinctions between the terms transgender and transsexual and their usage over time (see Davis, 2008; Wilchins, 2004, p. 26), within this study, the word transgender is utilized as a broad umbrella term that includes transsexuals in order to mirror the conceptualization of the transgender community utilized within the National Transgender Discrimination Survey and by both of the advocacy organizations that carried out this survey (Grant et al., 2011). 


\section{Literature Review}

Most universities today operate based on the assumptions that gender is binary and static. However, such assumptions do not match the lived experiences of transgender and gender nonconforming students (Beemyn, 2005b; Bilodeau, 2007; Seelman et al., 2012). Further, younger generations of transgender students do not always fit into a transsexual model of identity development whereby a person transitions from one sex to another, which is perhaps the more commonly understood subgroup within the transgender community (Beemyn, 2005b; Rankin \& Beemyn, 2012). Instead, some individuals identify outside of the gender binary or identify with multiple genders simultaneously (Beemyn, 2005b; Rankin \& Beemyn, 2012) and experience a lot of stress when trying to access campus spaces that are designated for either men or women.

Most of the existing research about transgender individuals' access to gender-segregated spaces in college has used qualitative methods and regional convenience samples. One of the key studies in this area was conducted by Bilodeau (2007) and focused on identifying the presence of genderism, or "the belief or assumption that there are two, and only two genders" (p. 71), within college settings. One of the four characteristics of genderism identified by Bilodeau-social accountability - is manifested in how transgender and gender variant people are punished by others through harassment, bullying, discrimination, and expulsion when their perceived gender identity or gender expression transgresses cultural norms. This social accountability is often strongly enforced within spaces such as dormitories, public bathrooms, locker rooms, and athletic facilities, eliciting feelings of fear and stress among trans people (Bilodeau, 2007).

Several studies have looked at transgender and gender non-conforming people's access to and experiences within campus housing. In a participatory research project involving interviews with 30 transgender students, staff, and faculty, Seelman et al. (2012) found that within campus 
housing, students experienced being outed as transgender, having issues of transgender inclusion put to a majority vote among all residents, and having difficulty getting information about housing options that were open to people of all genders. Bilodeau's (2007) participants discussed problems addressing roommate dynamics when one resident is transgender and having a lack of support and guidance about what bathroom to use when one's gender identity differs from that of other residents in one's dormitory.

Restrooms, locker rooms, and other similar facilities are also spaces where transgender individuals frequently face harassment and violence on campus. Finger (2010) found that bathroom access was one of the most frequent concerns discussed by 18 trans individuals; participants reported feeling fearful when bathroom stalls did not lock, and they desired safe, clean, and lockable spaces (Finger, 2010). Other researchers have documented that trans people often struggle to find bathrooms on campus that are safe and free of harassment (Seelman et al., 2012) and they are frequently stared at or questioned by others within such spaces (Bilodeau, 2007). Seelman et al. (2012) suggest that campus spaces that group people by gender and exclude non-binary and fluid identities contribute to outcomes of exclusion and invisibility for transgender campus members.

While there is scant research that statistically compares the risks for transgender discrimination in accessing spaces on college campuses for gender identity subgroups (e.g., trans women, trans men, gender non-conforming individuals, etc.), Serano (2007) posits that not all transgender subgroups experience discrimination in the same way and that trans women's experiences are deeply impacted not just by prejudices about transgressing the gender binary but also by misogyny (the devaluing of women). Particularly within women's spaces, people often try to justify denying access to trans women and gender non-conforming individuals by saying 
there is a need to "protect" cisgender women from "male predators" (Browne, 2004; Mottet \& Ohle, 2003). Such an argument not only conflates being trans or gender non-conforming with violence towards (cisgender) women, but also wrongly labels the gender identity of those denied access. Such theoretical work suggests a reason for exploring the differences between gender identity subgroups and particularly for comparing the experiences of trans women to other transgender and gender non-conforming people in accessing gender-segregated spaces.

Existing evidence indicates that "passing" (or being perceived by others as the gender with which one identifies) is a key factor within gender-segregated spaces that impacts whether one is denied access to the space and/or targeted for harassment and violence. The pressure to pass creates a situation of "extreme stress" for trans and gender non-conforming individuals because they must worry about whether they meet others' gendered standards in order to access spaces crucial to basic well-being, such as bathrooms and housing (Bilodeau, 2007, p. 92).

Seelman et al. (2012) have suggested a general pattern whereby individuals who are regularly read as their gender identity or as the gender assigned to the space being accessed are less likely to be challenged or harassed within that space.

\section{The Role of Social Workers}

Transgender individuals' experiences of exclusion, harassment, and discrimination in college housing, bathrooms, and other campus spaces should be of concern to social workers not only because of the profession's commitments to the dignity and worth of the individual and to social justice (NASW, 2008), but also because social workers hold many roles where they can contribute to positive change for the transgender community in colleges and universities. Such roles include being college educators who wish to support transgender students and work colleagues, being field instructors who are supervising social work students, and being clinicians 
for transgender individuals who have experienced previous trauma and rejection in such settings. Social work scholars are calling for practitioners to better understand the experiences of transgender individuals and the oppressive conditions they face (Burdge, 2007) and to "be fluent in trans-respect and in trans-discrimination in order to be effective advocates" (Clark, 2011, p. 47). The present study intends to contribute to this professional discourse and the growing empirical knowledge base in this area.

\section{Gaps in the Knowledge Base}

Existing research on transgender people in higher education settings has primarily utilized qualitative methodologies with limited generalizability. Due to a number of methodological challenges in sampling this population, there are also relatively few studies of transgender people that are national in scope. Of the existing studies of transgender individuals' experiences in higher education, few have looked at how experiences differ between subgroups within the transgender community, such as trans women compared to trans men or trans people of color compared to White trans people. Further, most research has used small samples that do not reflect racial or ethnic diversity, even though these dimensions of identity likely impact a trans person's experiences on a college campus. More research is greatly needed to explore how holding another marginalized identity or characteristic may impact a transgender or gender nonconforming person's experience as a student in higher education so that these settings can be transformed to meet the needs of the diversity of trans people in colleges and universities.

\section{Research Question}

Based on the gaps in the knowledge base, this study asks the research question: Among a national sample of transgender people who have attended a college or university, what personal and gender-related factors predict denial of access to genderappropriate housing and bathrooms/facilities on campus? 


\section{Methodology}

This study involves secondary data analysis of the National Transgender Discrimination Survey dataset, which was collected by NCTE and the Task Force between September 2008 and March 2009 (Grant et al., 2011). These organizations distributed the survey through contact with over 800 transgender-led and/or transgender-serving organizations across the country and 150 active listservs (Grant et al., 2011). Staff at the Task Force provided the author with an electronic copy of the de-identified dataset in SPSS format. This study was approved by the Institutional Review Board at the University of Denver on April 29, 2011.

\section{Sample}

In constructing the NTDS, the research teams affiliated with the Task Force and NCTE designed a sampling frame that included adult individuals who reported that they identified as transgender or gender non-conforming in any way (Grant et al., 2011). The survey design team used a broad definition of transgender that was intended to capture subgroups that may have differing experiences, including cross-dressers, transsexuals, and people who said that the term transgender did not apply at all to them, but who indicated a sex at birth that differed from their current gender identity. Participants were asked to identify their primary gender identity (including identifying part-time in different genders), as well as the degree to which various identity terms applied to them. Those who identified as a gender (male/man, or female/woman) different than their sex at birth were classified as transgender (either FTM or MTF, depending on the answers given). Those who indicated a sex that aligned with their primary gender identity, or who said their primary gender identity was either "part-time" between different genders or a gender not listed, were classified as either transgender or gender-nonconforming, depending upon precise answers. Most people classified as cross-dressers indicated that they had strongly 
identified with the term cross-dresser as their primary gender identity (Grant et al., 2011). The present study utilizes the gender identity categories as delineated by the NTDS research team, while recognizing that partitioning the sample into distinct gender subgroups artificially simplifies gender identification and ignores the experiences of those who may identify with more than one of these subgroups.

For the purposes of the present study, respondents who reported having a high school education or less, who said that they did not attend college, or who did not attend school as transgender were dropped from the analysis, leaving a sample of 2,772 respondents. Almost half $(42.6 \%, n=1,179)$ of the sample was classified as FTM transgender, 33.5\% $(n=927)$ were MTF transgender, $15.1 \%(n=418)$ were female to other/gender non-conforming/part time ${ }^{\mathrm{i}}, 4.4 \%(n=$ 122) were female to cross dress male, $2.2 \%(n=60)$ were male to cross dress female, and $2.1 \%$ ( $n=59)$ were male to other/gender non-conforming/part time. Table 1 provides an overview of other demographic details of the sample.

\section{| INSERT TABLE ONE HERE|}

\section{Measures}

Independent variables. Selection of variables was driven by structural social work theory, which suggests that experiences of institutional oppression differ according to one's identification within marginalized and/or privileged groups (Baskin, 2003; Mulé, 2008; Mullaly, 2007). Variables were also chosen based on what factors the literature suggests may play a role in a transgender person's access to housing, bathrooms, and other facilities in higher education. Two types of predictor variables were analyzed in this study: socio-demographic variables and gender-related variables. Each of these variable groups was tested in separate logistic regression models for the two dependent variables. The socio-demographic variables included: (a) annual 
household income (recoded into $\$ 10,000$ intervals, with the highest option being $\$ 100,000$ or above); (b) race (recoded as a White/non-White dummy variable for parsimony); (c) age; (d) age squared (to test for a curvilinear relationship between age and the dependent variables); (e) disability status (a dummy variable indicating whether participants had a physical, learning, or mental health disability other than a gender-related mental health diagnosis); (f) U.S. citizenship status (a citizen/non-citizen dummy variable); (g) college degree (a dichotomous variable indicating whether or not one had received a bachelor's degree or above); and (h) urbanicity (a dichotomous variable indicating whether one's current zip code was urban or rural, based on the U.S. Census Rural-Urban Commuting Area [RUCA] codes). While the historical timeframe during which participants attended college (e.g., the 1960s vs. 2010s) is likely an important factor in predicting experiences of transgender discrimination on campus, such data was not collected by the NTDS and therefore could not be accounted for in these statistical models. This issue is further discussed in the Limitations section of the paper.

Gender-related predictor variables were used to study the role of gender identity, medical transition status, and whether_ —as suggested by previous qualitative research—“passing" impacts one's access to gender-segregated spaces. Gender-related predictor variables included: (a) three dummy variables related to gender identity: one indicating FTM identity, a second indicating cross-dresser identity (MTF cross-dresser or FTM cross-dresser), and a third indicating gender non-conforming identity (male-to-other, female-to-other, a part-time gender identity, gender nonconforming, androgynous, genderqueer, and all other terms not listed); (b) a variable indicating whether people can tell that one is transgender or gender non-conforming (an ordinal variable with five responses ranging from Never to Always); and (c) medical transition history (a dichotomous variable indicating whether or not one has undergone any medical transition). MTF 
individuals acted as the comparison group for the gender identity variables because theoretical work suggests that this subpopulation of transgender people may face differential risks for discrimination, harassment, and victimization due to the overlap of transphobia and misogyny. Each participant in this study was grouped into only one gender identity category as part of these analyses.

Dependent variables. Two dichotomous dependent variables were examined using logistic regression models. These consisted of: (a) whether an individual was not allowed gender-appropriate housing on campus due to being transgender or gender non-conforming; and (b) whether an individual was not allowed to use appropriate bathrooms or other facilities at school due to being transgender or gender non-conforming.

\section{Statistical Analyses}

The researcher constructed the logistic regression models using the Statistical Package for the Social Sciences (SPSS), version 20. No variable had more than $8.9 \%$ missing data, and multiple imputation was utilized to impute data for all of the predictor variables. Five imputations were calculated, which is thought to be an adequate number as long as there are not large patterns of missing data that need to be imputed (Rubin, 1996). For each dependent variable, two different logistic regression models were constructed: one with socio-demographic predictor variables, and a second with gender-related predictor variables. The models are presented side-by-side to allow for a comparison of predictors across the two settings.

\section{Results}

\section{Descriptive Statistics}

Sociodemographic variables. Descriptive statistics related to sociodemographic predictor variables were detailed within Methodology section (see Table 1). 
Gender-related variables. Gender identity characteristics of the sample are described in the Methodology section. For the question regarding the frequency at which others perceive a person to be transgender or gender non-conforming, the mode response was "Occasionally," (28.0\%, $n=774)$, followed by “Sometimes," (24.9\%, $n=687)$, "Never," $(20.3 \%, n=560)$, "Most of the time," $(19.2 \%, n=531)$, and "Always" $(7.6 \%, n=211)$. More than half of the sample $(63.7 \%, n=1,757)$ indicated that they had sought hormone treatment or surgeries related to being transgender or gender non-conforming.

Dependent variables. Nearly one in five respondents $(19 \%, n=290)$ was not allowed to use gender-appropriate housing while a student on a school campus due to being transgender or gender non-conforming. Almost a quarter $(23.9 \%, n=478)$ of the sample was at some point not allowed to use appropriate bathrooms or other facilities at school while a student due to being transgender or gender non-conforming.

\section{Inferential Statistics}

Sociodemographic predictor variables models. Two direct binary logistic regression models were calculated to predict denial of access to school housing and bathrooms/other facilities. A comparison of the full model to the constant-only model before multiple imputation was statistically significant for both models (see Table 2$)^{\mathrm{ii}}$. Information about model fit $\mathrm{t}^{\mathrm{iii}}$ and Nagelkerke $R^{2}$ are provided in the table as well. The data in Table 2 indicate that this group of sociodemographic predictors was useful in distinguishing those who experienced discrimination in housing and bathrooms/other facilities at school from those who did not.

\section{| INSERT TABLE TWO HERE |}


The role of each of the sociodemographic predictor variables in predicting the two outcomes is more closely examined in Table 3. These models used the pooled data following multiple imputation.

\section{| INSERT TABLE THREE HERE |}

According to the Wald criterion, annual household income and having a bachelor's degree were significant predictors of whether a person was prohibited from accessing genderappropriate housing on campus due to being transgender or gender non-conforming. For every $\$ 10,000$ increase in annual household income, the odds of being denied access to genderappropriate housing on campus due to being transgender or gender non-conforming decreased by 8\%. Those who had less than a bachelor's degree were 1.38 times as likely as those who had a bachelor's degree or higher to have been denied gender-appropriate housing on a school campus when they were students due to being transgender or gender non-conforming.

For the model predicting access to bathrooms and other facilities, being a person of color, age squared, disability status, having a bachelor's degree, and urbanicity were all significant predictors of whether a person was prohibited from accessing appropriate bathrooms or other facilities on a school campus due to being transgender or gender non-conforming. Compared to White people, people of color were 1.39 times as likely to be denied access to appropriate bathrooms or other facilities on campus due to being transgender or gender non-conforming. The statistically significant result for the age squared variable meant that there was a curvilinear relationship between age and denial of access to an appropriate bathroom or other facility (see Figure 1). The likelihood of experiencing such discrimination peaks at approximately age 28 and then begins to decrease exponentially. Those who had a physical, learning or mental health disability other than a gender-related mental health diagnosis were 1.59 times as likely as those 
without a disability to have been denied access to appropriate bathrooms or other facilities. Those who had less than a bachelor's degree were 1.41 times as likely to have been denied appropriate bathrooms or other facilities on a school campus as those who had a bachelor's degree or above. Finally, those who lived in rural areas were 1.48 times as likely as those in urban areas to have been denied access to bathrooms or other facilities at school due to being transgender or gender non-conforming.

Gender-related predictor variables models. The last two regression models were calculated to predict denial of access to school housing and bathrooms/other facilities as a function of several gender-related variables. A comparison of the full models to the constantonly models before multiple imputation was statistically significant $(p<.001)$ (see Table 4$)$, which suggests that this group of gender-related variables was more useful than the constantonly model in distinguishing those who experienced discrimination in these spaces from those who did not.

\section{| INSERT TABLE FOUR HERE |}

Table 5 provides detail about the role of each of the gender-related variables in predicting denial of access to housing and bathrooms.

\section{| INSERT TABLE FIVE HERE |}

Gender identity played a statistically significant role in both of the models. Compared to those who were gender non-conforming, those who were male-to-female were $3.13^{\text {iv }}$ times as likely to have been denied access to gender-appropriate housing and 2.86 times as likely to have been denied access to bathrooms and other facilities on campus. Neither FTM individuals nor crossdressers were predicted to experience greater or lesser denial of access to gender-appropriate housing or bathrooms on campus than MTF individuals. Frequency of being perceived as 
transgender was statistically significant in predicting access to bathrooms and other facilities, but not housing: for each increase from one response category to the next highest ranked response category in frequency of being perceived as transgender without telling others (e.g., an increase from Never to Occasionally, or from Sometimes to Most of the Time), the odds of being denied access to appropriate bathrooms or other facilities at school increased by 1.28.

\section{Discussion}

The data from the National Transgender Discrimination Survey provide a picture of transgender people's experiences accessing gender-segregated spaces in higher education. While transgender people have been voicing these issues for some time, this study takes an important step of documenting the problem through empirical research. These data indicate that a notable proportion of transgender people who have attended higher education are not allowed to access gender-appropriate housing (19\%) and/or appropriate bathrooms and other facilities (23.9\%) while they are students. Considering that most of the previous research on this topic has been limited to small qualitative samples, these descriptive statistics are valuable in understanding the degree to which this population is kept out of such spaces. Note that these percentages encompass those respondents who were not allowed to use these spaces; the proportion who were able to use these spaces yet still faced questioning, harassment, or violence within them is likely even higher.

A key take-away point from the logistic regression models is that having multiple marginalized identities matters for students' access to spaces on campus - that is, transgender or gender non-conforming individuals tend to be at greater risk for being denied access to appropriate spaces (particularly bathrooms) when they hold another marginalized identity or characteristic. This pattern aligns with structural social work theory's expectations that 
institutions tend to work in a way that reproduces oppression and domination of marginalized groups (Mullaly, 2007). Such a finding is valuable to practitioners in that it suggests that higher education settings may present greater barriers for transgender people who are lower income, those who are people of color, those who have disabilities, etc. Thus, in order to change higher education institutions for the better, we need to utilize interventions that recognize intersectionality and acknowledge that not all transgender people experience the campus environment in the same way.

There are some differences in participants' experiences accessing school housing compared to bathrooms that may be related to who is denying transgender people access to these spaces. For example, applying for housing typically involves interactions with campus staff who may have access to written information about the individual's family income; further, those with greater socioeconomic status might use their social connections to advocate for access to appropriate housing for a transgender student in a way that is not possible for most lower income families. In contrast, interactions in bathrooms or locker rooms might not involve explicit awareness of a person's income or social class. Thus, as indicated by the data, transgender people with a lower annual household income are more likely than wealthier individuals to have been denied access to gender-appropriate housing, but not bathrooms/facilities, while attending a college/university. It should be noted, though, that the data collected about annual household income reflects current income; for those not currently in school, this amount may differ from the income they had while in college.

Since we know from qualitative research that transgender and gender non-conforming people may be challenged and harassed in bathrooms and locker rooms by just about anyone (strangers, acquaintances, staff, police, etc.) (Browne, 2004; Clark, 2011; Seelman et al., 2012) 
one could assume that such denial of access on university campuses is happening at the hands of fellow students as well as staff, faculty, administrators, and campus visitors. Such individuals may be particularly likely to judge whether a person should be allowed to use a bathroom based primarily on appearances and feel entitled to challenge certain subgroups' access. This is supported by the present study's findings: transgender people of color, those who are younger, those with a disability (physical, learning, or mental), and those more frequently perceived as transgender are more likely to be denied access to appropriate bathrooms or other facilities due to being transgender or gender non-conforming. The relationship between age and risk for being denied access to a bathroom is curvilinear: one's risk for being denied appropriate bathroom access peaks at about age 28 and then drops off exponentially. It is possible that young people in this sample may be more frequently perceived to be transgender or gender non-conforming compared to older transgender individuals, or that younger respondents are reporting this issue more frequently simply because such situations have happened more recently in their lives. The precise reasons for this finding related to age are unclear, but age does appear to play a role in whether a person is denied access to appropriate facilities on campus. This finding related to age should be interpreted with caution - as noted previously, the NTDS did not collect information about when participants enrolled in college, so the age variable alone cannot be used to understand differences in college experiences based upon historical context. Some of the older participants in this sample may have attended college within the past few years, while others may have attended decades ago, when campus climates and awareness of transgender and gender nonconforming people was very different.

The significance of disability status fits broader patterns about disabilities and access to space in college and university settings - that people with disabilities (physical or otherwise) 
frequently encounter greater institutional barriers to using spaces and buildings on campus (Nichols \& Quaye, 2009; Paul, 2000). In the gender-related predictor models, the item measuring the frequency at which one is perceived as transgender is perhaps the most direct indicator of transphobia. Its statistical significance in the bathroom/facilities model indicates that people on campus are actively policing and sanctioning trans people based on their perceived gender expression within bathrooms and other facilities and that "passing" as one's gender plays a role in whether one is challenged in such spaces. These patterns related to race, disability status, age, and the frequency at which one is perceived as transgender are only statistically significant for the bathrooms/facilities model (although the disability variable has marginal statistical significance in the housing model). Since decisions about housing access might sometimes occur without face-to-face interaction (e.g., by assessing paperwork), perhaps one's "visible" race, age, disability, or gender expression become less of a factor in such decisions.

Not having a college degree was a statistically significant predictor of greater risk of being denied access to both types of campus settings (housing and bathrooms). Note, however, that this should not be interpreted as indicating that transgender people are dropping out of college because of these experiences: the statistical models examined here provide evidence only to a statistical relationship between college degree and denial of equal access. These models cannot be interpreted as indicating a causal relationship between experiences of unequal access and college completion, or vice versa.

The degree to which one lived in an urban or rural zip code was only statistically significant in predicting bathroom access on campus. In situations where a transgender person's ability to access services could be denied by any person (e.g., in bathrooms), they face greater risk when living in a rural area; however, in situations where they are more likely interacting 
with a campus staff person (e.g., in accessing housing), there is no difference in risk based on urbanicity of residence.

There are some distinct differences in on-campus experiences based upon gender identity. MTF individuals face greater risk for denial of access to both gender-appropriate housing and to appropriate bathrooms and other facilities compared to those who are gender non-conforming. This result indicates that trans women face particular gender policing in housing and bathrooms that frequently prohibits them from accessing spaces designated for women, whereas similar experiences are less likely for those who identify as gender non-conforming. This issue relates to two dynamics - (a) the pattern of questioning the authenticity of trans women as "true" women; and (b) the societal norm that assumes that women (and "women-only" spaces) should be protected from potential male predators through the exclusion of trans women (see, for example, Connell, 2011). Both of these dynamics are problematic because they uphold cisgender (nontransgender) identities as the norm (and treat transgender women as "fake" women) and conflate being transgender with predatory behaviors against women. Campus administrators and staff need to take further actions to ensure that trans women can access gender-appropriate housing and bathrooms that match their gender identity and that will be safe for the individual; access to such spaces should be tied to a person's gender identity, rather than sex assigned at birth.

It is important to note that denial of access to campus spaces experienced by MTF individuals did not differ significantly from that of either FTM individuals or cross-dressers, even when controlling for the frequency at which a person is perceived by others as transgender. This finding indicates that there may be more at play in predicting denial of access to spaces than just an individual's gender identity, such as where one is in a transition process, the general 
culture and level of trans acceptance on a particular campus, and whether a person is trying to access men's spaces or women's spaces.

\section{Limitations}

One of the limitations of this project is that the data do not come from a random sample. However, the NCTE/Task Force sample is among the largest samples ever collected of transgender people and roughly mirrors the U.S. population distribution (Grant et al., 2011), both of which are factors that add to the impact of findings, especially given the dearth of quantitative research about this issue. The NTDS dataset was limited by the lack of questions about whether respondents were currently enrolled in school, their current grade level, and when they had graduated from or last attended college. Since these questions were not asked, the present analyses include both participants currently enrolled in college, graduates, and those who had dropped out. The age and age squared variables are the best stand-ins for generational differences, although not equivalent replacement measures, since respondents who are the same age may have attended college in different historical contexts when the degree of acceptance and knowledge of transgender and gender non-conforming individuals was not the same. Regardless of these measurement issues, the data provide a broad overview of the experiences of transgender people in accessing campus spaces across age groups.

Another limitation was that the survey questions used for the two dependent variables did not specify the level of schooling being discussed. Although these questions appeared next to other items relevant to higher education (e.g., financial aid) and the question about campus housing is likely referencing college settings for most respondents, participants may have answered the questions as if speaking to K-12 settings rather than higher education. To help minimize this measurement concern, the sample only included those who had attended college, 
although these dependent variables will still have measurement error related to this issue. Finally, because this study involved a one-time survey of transgender and gender non-conforming people, these data cannot infer causality. Thus, while the logistic regression models may indicate statistically significant relationships between the various predictors, they cannot be interpreted as indicating a causal relationship.

\section{Implications for Social Workers}

The results from this research have relevance to social workers and those in higher education settings and can help change policies, procedures, and activities that impede the full participation of campus members who are transgender and gender non-conforming. Some recommendations for improving campus practices and policies include:

- Expect that a sizeable group of trans individuals on any college campus have had the experience of being denied access to housing or bathrooms and may benefit from support and advocacy from others in gaining access to safe and gender-appropriate spaces.

- Recognize the importance of intersectionality in college experiences and how trans people face differential risks for denial of access to spaces based upon characteristics such as disability status, race/ethnicity, income, etc.

- As indicated by the present study, the frequency that an individual is perceived as transgender predicts denial of access to bathrooms. Therefore, it is important to educate those on campus that it is not okay to refuse bathroom access to individuals simply based upon gender identity and expression and that bathroom access is a basic right for all campus members. Bathroom use policies should emphasize appropriate behaviors rather than appropriate gender identity or gender expression. 
- Recognize that MTF individuals may be at particularly heightened risk for being denied access to women's spaces due to stereotyped assumptions that they are predators and/or not "real" women.

- Develop spaces that are welcoming and safe for people of all genders by creating allgender or single housing options, private changing rooms, single stall restrooms, and restrooms that are open to people of any gender (Bilodeau, 2007; Clark, 2011; Markman, 2011). Widely advertise the availability of gender-neutral and single-stall restrooms on a campus map so that people are aware of the availability of such spaces (Mintz, 2011).

- Offer gender-blind housing options. Ask all housing applicants to designate if they would prefer sharing a room/floor with women, men, or both. Have alternate housing options for transgender and gender non-conforming individuals who, for safety reasons, would rather not have a roommate (e.g., single-occupancy dorm rooms).

\section{Implications for Future Research}

Future researchers might use the findings from this study to develop and test instruments for assessing denial of access to spaces and campus services. Scholars could examine whether transgender people's experiences differ between campuses that have differing policies (e.g., nondiscrimination policies that include transgender people) and facility options (e.g., genderneutral bathrooms). It may also be beneficial to examine who is denying transgender people access to housing, bathrooms, and facilities - whether it is campus staff, faculty, students, or others - and in what type of gendered spaces these experiences are happening (men's, women's, or mixed gender spaces). Future researchers may want to compare other gender identity subgroups (e.g., FTM vs. gender non-conforming individuals) that were not compared in this study or examine interaction terms between demographic or gender-related characteristics to see 
how risk for denial of access to space is impacted by the overlap of identities (e.g., being transgender, a person of color, AND low-income).

\section{Conclusion}

This study fills a number of gaps in scholarship about transgender and gender nonconforming people's experiences accessing gendered spaces within college and university settings. This research is among the first to use a large, national sample to examine this topic and uniquely integrates community-based quantitative data. By conducting statistical analyses that examine sociodemographic and gender-related characteristics, this study moves the knowledge base from a more exploratory framework to one that can begin to predict risks and examine within-group differences in access to campus spaces. This approach reveals some key differences in experiences of unequal treatment between subgroups of the transgender community — such as people of color, those with disabilities, and different gender identity groups — that can help guide social workers in understanding the heightened risk for denial of access to sex-segregated spaces for individuals with multiple marginalized identities. As Burdge (2007) points out, social workers are "[well-]positioned to take a closer look at the societal forces impinging on the lives of transgendered people and consider ways to dismantle the oppressive gender structure in society" (p. 249). 
Running head: TRANSGENDER ACCESS TO HOUSING AND BATHROOMS

\section{References}

Baskin, C. (2003). Structural social work as seen from an aboriginal perspective. In W. Shera (Ed.), Emerging perspectives on anti-oppressive practice (pp. 65-79). Toronto, Ontario, Canada: Canadian Scholars’ Press.

Beemyn, B. (2005a). Making campuses more inclusive of transgender students. Journal of Gay \& Lesbian Issues in Education, 3(1), 77-87. doi:10.1300/J367v03n01_08

Beemyn, B. G. (2005b). Trans on campus: Measuring and improving the climate for transgender students. On Campus with Women, 34(3). Retrieved from http://www.aacu.org/ocww/volume34_3/feature.cfm?section=2

Beemyn, B., Curtis, B., Davis, M., \& Tubbs, N. J. (2005). Transgender issues on college campuses. New Directions for Student Services, 111, 49-60. Retrieved from http://onlinelibrary.wiley.com/journal/10.1002/(ISSN)1536-0695 Burdge, B. J. (2007). Bending gender, ending gender: Theoretical foundations for social work practice with the transgender community. Social Work, 52(3), 243-250.

Bilodeau, B. L. (2007). Genderism: Transgender students, binary systems and higher education (Doctoral dissertation). Retrieved from ProQuest Dissertations and Theses Database. (UMI No. 3264140)

Browne, K. (2004). Genderism and the bathroom problem: (Re)materialising sexed sites, (re)creating sexed bodies. Gender, Place and Culture: A Journal of Feminist Geography, 11(3), 331-346. doi:10.1080/0966369042000258668

Burdge, B. J. (2007). Bending gender, ending gender: Theoretical foundations for social work practice with the transgender community. Social Work, 52(3), 243-250. Retrieved from http://www.naswpress.org/publications/journals/sw.html 
Campus Pride Trans Policy Clearinghouse. (n.d.). Colleges and universities with nondiscrimination policies that include gender identity/expression. Retrieved from http://www.campuspride.org/tpc-nondiscrimination/

Clark, C. R. (2011). Rethinking gendered spaces: Bathrooms and safe access for trans people (Master's thesis). Retrieved from Sacramento State ScholarWorks: http://csusdspace.calstate.edu/handle/10211.9/1054

Connell, C. (2011). The politics of the stall: Transgender and genderqueer workers negotiating “the bathroom question.” In C. Bobel \& S. Kwan (Eds.), Embodied resistance: Challenging the norms, breaking the rules (pp. 175-185). Nashville, TN: Vanderbilt University Press.

Davis, C. (2008). Social work practice with transgender and gender nonconforming people. In G. P. Mallon (Ed.), Social work practice with lesbian, gay, bisexual, and transgender people (2nd ed., pp. 83-111). New York, NY: Routledge.

Finger, E. F. (2010). Beyond the binary: Serving the transgender student, improving the college experience (Doctoral dissertation). Available from ProQuest Dissertations and Theses database. (UMI No. 3445367)

Grant, J. M., Mottet, L. A., Tanis, J., Harrison, J., Herman, J. L., \& Keisling, M. (2011). Injustice at every turn: A report of the National Transgender Discrimination Survey. Washington, D.C.: National Center for Transgender Equality and National Gay and Lesbian Task Force. Retrieved from http://transequality.org/PDFs/NTDS_Report.pdf

Hines, S. (2010). Introduction. In S. Hines \& T. Sanger (Eds.), Transgender identities: Towards a social analysis of gender diversity (pp. 1-22). New York, NY: Routledge. 
Markman, E. R. (2011). Gender Identity Disorder, the gender binary, and transgender oppression: Implications for ethical social work. Smith College Studies in Social Work, 81(4), 314327. doi:10.1080/00377317.2011.616839

Mintz, L. M. (2011). Gender variance on campus : A critical analysis of transgender voices (Doctoral Dissertation). Retrieved from ProQuest Dissertations and Theses Database. (UMI no. 3468787)

Mottet, L., \& Ohle, J. M. (2003). Transitioning our shelters: A guide to making homeless shelters safe for transgender people. New York, NY: The National Coalition for the Homeless and the National Gay and Lesbian Task Force Policy Institute. Retrieved from the National Gay and Lesbian Task Force website: http://www.thetaskforce.org/ downloads/reports/reports/Transitioningourshelters.pdf

Mulé, N. J. (2008). Demarcating gender and sexual diversity on the structural landscape of social work. Critical Social Work, 9(1). Retrieved from http://www.uwindsor.ca/ criticalsocialwork/demarcating-gender-and-sexual-diversity-on-the-structural-landscapeof-social-work

Mullaly, R. (2007). The new structural social work (3rd ed.). Don Mills, Ontario, Canada: Oxford University Press.

National Association of Social Workers. (2008). Code of ethics of the National Association of Social Workers. Retrieved from http://www.socialworkers.org/pubs/code/code.asp Nichols, A. H., \& Quaye, S. J. (2009). Beyond accommodation: Removing barriers to academic and social engagement for students with disabilities. In S. R. Harper \& S. J. Quaye (eds.), Student engagement in higher education (pp. 39 -60). New York, NY: Routledge. 
Paul, S. (2000). Students with disabilities in higher education: A review of the literature. College Student Journal, 34(2), 200-211.

Rankin, S., \& Beemyn, G. (2012). Beyond a binary: The lives of gender-nonconforming youth. About Campus, 17(4): 2-10. doi:10.1002/abc.21086

Rubin, D. B. (1996). Multiple imputation after 18+ Years. Journal of the American Statistical Association, 91(434), 473-489.

Seelman, K. L. (2013). A mixed methods examination of structural bigenderism and the consequences for transgender and gender variant people (Doctoral dissertation). Retrieved from ProQuest Dissertation \& Theses Database. (UMI No. 3588397)

Seelman, K. L., Walls, N. E., Costello, K., Steffens, K., Inselman, K., Montague-Asp, H., \& Colorado Trans on Campus Coalition. (2012). Invisibilities, uncertainties and unexpected surprises: The experiences of transgender and gender non-conforming students, staff, and faculty at colleges and universities in Colorado. Retrieved from https://portfolio.du.edu/ewalls2

Serano, J. (2007). Whipping girl: A transsexual woman on sexism and the scapegoating of femininity. Berkeley, CA: Seal Press.

U.S. Department of Education. (n.d.). Recent high school completers and their enrollment in 2year and 4-year colleges, by sex: 1960 through 2010. Retrieved from http://nces.ed.gov/programs/digest/d11/tables/dt11_209.asp

Wilchins, R. (2004). Queer theory, gender theory: An instant primer (1st ed.). Los Angeles, CA: Alyson Books. 
Table 1

Demographics of sample $(\mathrm{N}=2,772)$

\begin{tabular}{|c|c|}
\hline Demographic & Descriptive Statistics \\
\hline Age & $\begin{array}{l}\text { Range: } 18-76 \\
M=32.20(S D=10.93), \text { median }=28\end{array}$ \\
\hline Race/ethnicity & $\begin{array}{l}74.2 \%(n=2,037) \text { White } \\
15.6 \%(n=432) \text { Multiracial/mixed race } \\
3.6 \%(n=98) \text { Black/African American } \\
6.4 \%(n=179) \text { All others }\end{array}$ \\
\hline $\begin{array}{l}\text { Urbanicity (based on } \\
\text { RUCA 2.0 Census } \\
\text { designations) }\end{array}$ & $\begin{array}{l}91.6 \%(n=2,459) \text { urban } \\
8.4 \%(n=225) \text { large rural town, small rural town, or isolated }\end{array}$ \\
\hline Disability status & $32.5 \%(n=902)$ had a physical, learning or mental disability \\
\hline $\begin{array}{l}\text { Current annual } \\
\text { household income }\end{array}$ & $\begin{array}{l}\text { Range: less than } \$ 10,000 / \text { year to over } \$ 250,000 / \text { year } \\
\text { mode = less than } \$ 10,000 / \text { year } \\
\text { median = between } \$ 30,000 \text { to } \$ 39,999 / \text { year }\end{array}$ \\
\hline $\begin{array}{l}\text { Educational } \\
\text { attainment }\end{array}$ & $\begin{array}{l}56.4 \%(n=1,562) \text { bachelor's degree or above } \\
43.6 \%(n=1,210) \text { education beyond high school, but less than a } \\
\text { bachelor's degree }\end{array}$ \\
\hline Citizenship status & $\begin{array}{l}96.7 \%(n=2,670) \text { U.S. citizens } \\
2.0 \%(n=56) \text { documented non-citizen } \\
1.3 \%(n=35) \text { undocumented non-citizen }\end{array}$ \\
\hline
\end{tabular}


Table 2

Model Fit and Nagelkerke $R^{2}$ for the Two Models Before Multiple Imputation:

Sociodemographic Predictor Variables

\begin{tabular}{lcccc}
\hline $\begin{array}{c}\text { Dependent Variable } \\
(N \text { before imputation })\end{array}$ & \multicolumn{2}{c}{-2 Log Likelihood } & $\begin{array}{c}\text { Model Fit }\left(\chi^{2}\right) \\
d f=8\end{array}$ & $\begin{array}{c}\text { Nagelkerke } \\
R^{2}\end{array}$ \\
\hline & $\begin{array}{c}\text { Constant- } \\
\text { only model }\end{array}$ & Full model & & \\
\hline $\begin{array}{l}\text { Gender-Appropriate } \\
\text { Housing } \\
(N=1,344)\end{array}$ & 1314.59 & 1264.43 & $50.16^{* * *}$ & .06 \\
$\begin{array}{l}\text { Appropriate Bathrooms } \\
\text { \& Other Facilities } \\
(N=1,787)\end{array}$ & 1972.14 & 1899.89 & $72.25^{* * * *}$ & .06 \\
\hline$* * * p<.001$. & & & \\
\hline
\end{tabular}


Table 3

Logistic Regression Models Predicting the Two Dependent Variables as a Function of Sociodemographic Variables (Pooled Data)

\begin{tabular}{|c|c|c|c|c|}
\hline \multirow[b]{2}{*}{$\begin{array}{l}\text { Predictor } \\
\text { Variables }\end{array}$} & \multicolumn{2}{|c|}{$\begin{array}{c}\text { Gender-Appropriate } \\
\text { Housing } \\
(N=\mathbf{1 , 5 2 5}) \\
\end{array}$} & \multicolumn{2}{|c|}{$\begin{array}{l}\text { Access to Bathrooms or } \\
\text { Other Facilities } \\
(N=\mathbf{2 , 0 0 1})\end{array}$} \\
\hline & $\begin{array}{c}B \\
\text { (s.e.) }\end{array}$ & $\begin{array}{l}\text { Odds } \\
\text { Ratio }\end{array}$ & $\begin{array}{c}B \\
\text { (s.e.) }\end{array}$ & $\begin{array}{l}\text { Odds } \\
\text { Ratio }\end{array}$ \\
\hline $\begin{array}{l}\text { Annual } \\
\text { Household } \\
\text { Income }\end{array}$ & $\begin{array}{c}-0.09 * * * \\
(0.02)\end{array}$ & 0.92 & $\begin{array}{l}-0.03^{\wedge} \\
(0.02)\end{array}$ & 0.97 \\
\hline Race & $\begin{array}{c}0.21 \\
(0.15)\end{array}$ & 1.23 & $\begin{array}{c}0.33 * * \\
(0.12)\end{array}$ & 1.39 \\
\hline Age & $\begin{array}{c}0.02 \\
(0.06)\end{array}$ & 0.68 & $\begin{array}{c}0.06 \\
(0.04)\end{array}$ & 1.06 \\
\hline $\begin{array}{l}\text { Age } \\
\text { Squared }\end{array}$ & $\begin{array}{l}-9.75 \times 10^{-4} \\
\left(8.15 \times 10^{-4}\right)\end{array}$ & $9.99 \times 10^{-1}$ & $\begin{array}{c}-1.11 \times 10^{-3 *} \\
\left(5.13 \times 10^{-4}\right)\end{array}$ & $9.99 \times 10^{-1}$ \\
\hline $\begin{array}{l}\text { Disability } \\
\text { status }\end{array}$ & $\begin{array}{l}0.26^{\wedge} \\
(0.14)\end{array}$ & 1.30 & $\begin{array}{c}0.47 * * * \\
(0.11)\end{array}$ & 1.59 \\
\hline $\begin{array}{l}\text { Citizenship } \\
\text { status }\end{array}$ & $\begin{array}{c}0.18 \\
(0.35)\end{array}$ & 1.20 & $\begin{array}{l}0.47^{\wedge} \\
(0.11)\end{array}$ & 1.60 \\
\hline $\begin{array}{l}\text { College } \\
\text { Degree }\end{array}$ & $\begin{array}{l}0.32 * \\
(0.14)\end{array}$ & 1.38 & $\begin{array}{c}0.34 * * \\
(0.11)\end{array}$ & 1.41 \\
\hline Urbanicity & $\begin{array}{l}-0.06 \\
(0.25)\end{array}$ & 0.95 & $\begin{array}{l}0.39 * \\
(0.19)\end{array}$ & 1.48 \\
\hline (Constant) & $\begin{array}{l}-1.16 \\
(0.90)\end{array}$ & & $\begin{array}{l}-2.15 \\
(0.64)\end{array}$ & \\
\hline
\end{tabular}


Table 4

Model Fit and Nagelkerke $R^{2}$ for the Two Models Before Multiple Imputation: Gender-related

Predictor Variables

\begin{tabular}{|c|c|c|c|c|}
\hline \multirow[t]{2}{*}{$\begin{array}{l}\text { Dependent Variable } \\
\text { ( } N \text { before imputation) }\end{array}$} & \multicolumn{2}{|c|}{-2 Log Likelihood } & \multirow[t]{2}{*}{$\begin{array}{l}\text { Model Fit }\left(\chi^{2}\right) \\
\qquad d f=5\end{array}$} & \multirow[t]{2}{*}{$\begin{array}{c}\text { Nagelkerke } \\
R^{2}\end{array}$} \\
\hline & $\begin{array}{l}\text { Constant- } \\
\text { only model }\end{array}$ & Full model & & \\
\hline $\begin{array}{l}\text { Gender-Appropriate } \\
\text { Housing } \\
(N=1,510)\end{array}$ & 1474.46 & 1441.93 & $32.53 * * *$ & .03 \\
\hline $\begin{array}{l}\text { Appropriate Bathrooms } \\
\& \text { Other Facilities } \\
(N=1,986)\end{array}$ & 2185.10 & 2128.35 & $56.75 * * *$ & .04 \\
\hline
\end{tabular}


Table 5

Logistic Regression Models Predicting the Two Dependent Variables as a Function of Genderrelated Predictor Variables (Pooled Data)

\begin{tabular}{|c|c|c|c|c|}
\hline \multirow[b]{2}{*}{$\begin{array}{l}\text { Predictor } \\
\text { Variables }\end{array}$} & \multicolumn{2}{|c|}{$\begin{array}{c}\text { Gender-Appropriate } \\
\text { Housing } \\
(N=\mathbf{1 , 5 2 5})\end{array}$} & \multicolumn{2}{|c|}{$\begin{array}{c}\text { Access to Bathrooms or } \\
\text { Other Facilities } \\
(N=\mathbf{2 , 0 0 1})\end{array}$} \\
\hline & $\begin{array}{c}B \\
\text { (s.e.) }\end{array}$ & $\begin{array}{l}\text { Odds } \\
\text { Ratio }\end{array}$ & $\begin{array}{c}B \\
\text { (s.e.) }\end{array}$ & $\begin{array}{l}\text { Odds } \\
\text { Ratio }\end{array}$ \\
\hline FTM & $\begin{array}{c}0.07 \\
(0.16)\end{array}$ & 1.08 & $\begin{array}{l}-0.08 \\
(0.12)\end{array}$ & 0.92 \\
\hline Cross-Dresser & $\begin{array}{l}-0.13 \\
(0.30)\end{array}$ & 0.88 & $\begin{array}{l}-0.21 \\
(0.26)\end{array}$ & 0.81 \\
\hline $\begin{array}{l}\text { Gender Non- } \\
\text { Conforming }\end{array}$ & $\begin{array}{c}-1.14 * * * \\
(0.26)\end{array}$ & 0.32 & $\begin{array}{c}-1.06 * * * \\
(0.21)\end{array}$ & 0.35 \\
\hline $\begin{array}{l}\text { Frequency } \\
\text { Perceived as } \\
\text { Transgender }\end{array}$ & $\begin{array}{c}0.04 \\
(0.06)\end{array}$ & 1.05 & $\begin{array}{c}0.24 * * * \\
(0.05)\end{array}$ & 1.28 \\
\hline $\begin{array}{l}\text { Medical } \\
\text { Transition }\end{array}$ & $\begin{array}{l}-0.20 \\
(0.17)\end{array}$ & 0.82 & $\begin{array}{l}-0.11 \\
(0.14)\end{array}$ & 0.89 \\
\hline (Constant) & $\begin{array}{l}-1.29 \\
(0.28)\end{array}$ & & $\begin{array}{l}-1.55 \\
(0.23)\end{array}$ & \\
\hline
\end{tabular}

$* * * p<.001$. 


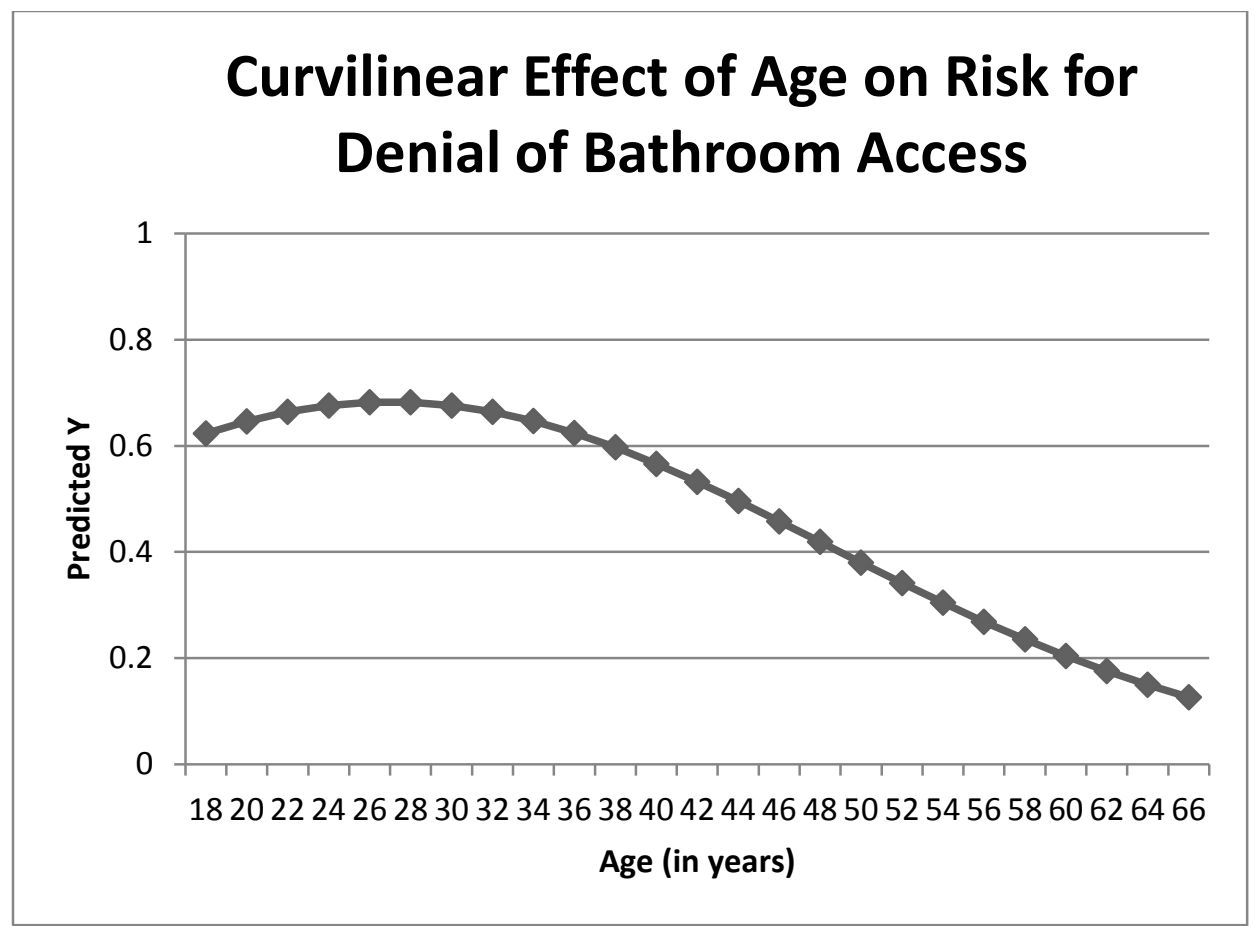

Figure 1. Curvilinear relationship between age and risk of being denied access to genderappropriate bathrooms in school settings, where a Y score closer to one indicates a greater likelihood of denial of access.

\footnotetext{
i The NCTE survey asked participants to designate their primary gender identity today. One response option was "part time as one gender, part time as another," which captures those who either are just beginning to transition or who may identify with different genders in different contexts. This subgroup of transgender people has received little attention in the literature (Grant et al., 2011).

ii Tables $2-5$ and Figure 1 are adapted from Seelman, 2013.

iii The data presented here for model fit and Nagelkerke $R^{2}$ are for the original data prior to multiple imputation. SPSS version 20 does not produce pooled results for model fit and Nagelkerke $R^{2}$ for imputed data.

iv This statistic is calculated using the inverse odds ratio: $1 / 0.32=3.13$.
} 